$p$-ISSN 1693-9484, $e$-ISSN : 2621-8313

Majalah Ilmiah Bahari Jogja (MIBJ)

Vol. 17 No. 2, Juli $2019 \quad$ (61-72)

DOI : $10.33489 /$ mibj.v17i2.210

(C) 2019 Akademi Maritim Yogyakarta

\title{
Simulasi Pelayanan Terminal Petikemas dalam Bidang Receiving Cargo Berbasis Software Sparkol Videoscribe
}

\author{
Suyanti ${ }^{1 *}$, Cahya Purnomo ${ }^{1}$ \\ ${ }^{1}$ Ketalaksanaan Pelayaran Niaga, Akademi Maritim Yogyakarta, Jl. Magelang KM 4.4, \\ Yogyakarta 55284, Indonesia \\ * Corresponding Author. Email:syandanish106@gmail.com. Telp:081357840120
}

\begin{abstract}
Abstrak
Penelitian ini meneliti pelaksanaan pengembangan media pembelajaran menggunakan sparkol videoscribe guna meningkatkan hasil belajar mahasiswa pada Mata Kuliah Manajemen Petikemas pada Prodi Ketatalaksanaan Pelayaran Niaga Akademi Maritim Yogyakarta. Penelitian ini menggunakan pendekatan kualitatif dan kuantitatif. Pengumpulan data dan informasi dilakukan menggunakan metode observasi, angket dan studi dokumentasi. Metode yang digunakan peneliti adalah metode perancangan dan penelitian pengembangan (Design and Development Research) dengan prosedur penelitian ADDIE (Analysis, Design, Development, Implementation, Evaluation). Data diuji menggunakan analisis $N$ Gain. Hasil penelitian mendapatkan kesimpulan pelaksanaan pengembangan media pembelajaran menggunakan sparkol videoscribe dapat meningkatkan hasil belajar mahasiswa. Hal ini dapat diketahui dari dua fakta, yaitu: 1) Berdasarkan hasil dari validasi ahli media, diperoleh hasil penilaian mutu teknis $67.50 \%$ yang masuk dalam kategori baik dan nilai aspek media $77.88 \%$ yang masuk dalam kategori sangat baik. Berdasarkan hasil dari validasi ahli materi, diperoleh hasil penilaian aspek media $86.11 \%$ dan aspek kesesuaian materi $81.25 \%$ dimana kedua aspek tersebut masuk kedalam kategori sangat baik. 2) Adanya peningkatan nilai rata-rata minat belajar taruna sebelum dan sesudah menggunakan media sparkol videoscribe yaitu dari 64.67 menjadi 79.67. Berdasarkan hasil uji $N$-gain, peningkatan minat belajar taruna mendapat nilai gain sebesar 0.43 yang termasuk dalam kategori sedang.
\end{abstract}

Kata Kunci: Simulasi Pelayanan Terminal Petikemas, Receiving Cargo,
Berbasis Software Sparkol Videoscribe, Mata Kuliah Manajemen Petikemas

\begin{abstract}
This study examines the implementation of learning media development using videoscribe sparkol in order to improve student learning outcomes in Container Management Courses at the Yogyakarta Commercial Shipping Maritime Academy Study Program.

This study uses a qualitative and quantitative approach. Data and information collection was carried out using observation, questionnaires and documentation studies. The method used by researchers is Design and Development Research with ADDIE research procedures (Analysis, Design, Development, Implementation, Evaluation). Data was tested using N-Gain analysis.
\end{abstract}


The results of the study concluded that the implementation of learning media development using videoscribe sparkol can improve student learning outcomes. This can be seen from two facts, namely: 1) Based on the results of media expert validation, technical quality assessment obtained results $67.50 \%$ in the good category and the media aspect value results $77.88 \%$ included in the excellent category. Based on the results of the material expert validation, the results of media aspect assessment is $86.11 \%$ and the result of material conformity aspects were $81.25 \%$. Both aspects were included in the excellent category. 2) There is an increase in the average value of interest in learning cadets before and after using videoscribe sparkol media, from 64.67 to 79.67. Based on the results of the N-gain test, an increase in interest in learning cadets gained a gain of 0.43 which is included in the medium category.

\section{Keywords: Container Terminal Service Simulation, Receiving Cargo, Sparkol} Videoscribe Software Based, Container Management Course

\section{PENDAHULUAN}

Software Sparkol Videoscribe merupakan teknologi informasi yang dikembangkan oleh salah satu perusahaan yang ada di Inggris, tepatnya pada tahun 2012. Aplikasi ini adalah sarana pembelajaran yang sangat membantu memberikan pemahaman kepada peserta didik. Pemanfaatan teknologi informasi ditujukan untuk meningkatkan kualitas pembelajaran sehingga dapat meningkatkan kualitas pendidikan (Lantip \& Riyanto, 2011: 5).

Menurut Joyce dan B. White (dalam Wulandari, 2016: 63) sparkol videoscribe adalah software yang menciptakan animasi gaya papan tulis singkat untuk menjelaskan konsep tertentu baik dibuat oleh instruktur (pendidik) maupun peserta didik. Penyajian videonya yang menarik menjadikan peserta didik lebih mudah untuk memahami pembelajaran sehingga dapat meningkatkan hasil belajar peserta didik. Hal ini sesuai dengan teori dari Arsyad (2011:23) yang menyatakan: Kualitas belajar dapat ditingkatkan bilamana integrasi kata dan gambar sebagai media pembelajaran dapat mengkomunikasikan elemen-elemen pengetahuan dengan cara yang terorganisasi dengan baik, dan jelas.

Berdasarkan pra riset yang dilakukan oleh peneliti di Akademi Maritim Yogyakarta terlihat bahwa kondisi pendidik, masih menyajikan pembelajaran dalam bentuk yang sederhana dan konvensional. Misalnya dosen masih menggunakan media papan tulis untuk menunjang proses pembelajaran di kelas. Selain itu, pada saat dosen menggunakan media proyektor untuk membantu memudahkan proses pembelajaran di kelas, hanya ditampilkan materi-materi pelajaran tanpa memberikan animasi dan video yang dapat membuat taruna merasa jenuh dan bosan.

Penggunaan variasi media pembelajaran di kelas dapat memudahkan taruna dalam memahami pelajaran dan membuat mereka tertarik mengikuti materi yang disampaikan. Hal tersebut memberikan dampak positif pada hasil belajarnya.

\section{Terminal Petikemas}

Terminal petikemas adalah terminal tempat dilakukannya pengumpulan petikemas dari hinterland ataupun pelabuhan lainnya untuk selanjutnya diangkut 
ke tempat tujuan atau terminal petikemas (Unit Terminal Container disingkat UTC) yang lebih besar lagi (Amir, 1997).

Menurut Arwinas (2000) unsur-unsur terminal petikemas:

1. Dermaga

Dermaga adalah tempat kapal ditambatkan di pelabuhan.

2. Lapangan penumpukan

Lapangan penumpukan adalah sebuah lahan yang luas untuk menempatkan container.

3. Alat bongkar muat

Pada terminal petikemas modern peralatan yang dipergunakan meliputi keran darat (quay crane/gantry crane) - warna biru, RTG (Rubber tired gantry) warna merah, atau T/C (Transfer Crane), dan trailer truck-chassis (Amir, 1997).

4. Terminal Operasional System (TOPS)

Terminal operasional system adalah sebuah sistem yang

berfungsi untuk mengatur segala kegitan yang dijalankan dalam area terminal pelabuhan (Sudjatmiko, 2006).

\section{Receiving/Penerimaan}

Menurut Keputusan Menteri Perhubungan KM No. 14 Tahun 2000 tentang Penyelenggaraan dan Pengadaan Bongkar Muat Barang ke dan dari Kapal, receiving adalah kegiatan memindahkan barang dari tempat penumpukan di lapangan untuk diserahkan sampai tersusun di atas kendaraan.

Warpani (2002) mengatakan menurut makna kamus recive adalah menerima. Selain itu menurut Suyono (2007: 143) receiving adalah kegiatan menerima barang atau muatan dari wilayah pelabuhan. Menurut Arwinas (2000: 23) receiving adalah kegiatan penerimaan barang ke dalam gudang.

Berdasarkan pengertian receiving dari para ahli dapat disimpulkan bahwa receiving merupakan kegiatan penerimaan muatan untuk disimpan sementara di dalam gudang. Pengertian gudang di sini adalah gudang CFS (Container Freight Station) yang merupakan kawasan untuk menimbun petikemas LCL (Less than Container Load), melaksanakan Stuffing dan Stripping dan untuk menimbun breakbulk cargo yang akan di-stuffing ke petikemas atau di-stripping dari petikemas (Suyono, 2007: 283).

\section{Cargo}

Cargo (kargo) didefinisikan sebagai semua barang yang dikirim melalui udara (pesawat terbang), laut (kapal), atau darat (truk/container) yang biasanya untuk diperdagangkan, baik antar wilayah/kota di dalam negeri maupun antar negara (internasional) yang dikenal dengan istilah ekspor-impor (Warpani, 2002: 95).

Menurut Sudjatmiko (2006: 64) muatan kapal atau cargo adalah segala macam barang dan barang dagangan yang diserahkan kepada pengangkut untuk diangkut dengan kapal, guna diserahkan di pelabuhan tujuannya.

Menurut Banu Santoso (1998: 133) kegiatan receiving cargo dari shipper sampai dimuat ke kapal (handling container) adalah: 
1. Stuffing yaitu kegiatan mengisi atau memasukkan barang ke dalam container dengan menggunakan tenaga buruh atau alat yang dinamakan Forklift.

2. Angsur, yaitu kegiatan memindahkan container di lapangan $C F S$ dengan tidak menggunakan trailer yang terjadi pada container $C F S$.

3. Lift On/Lift Off yaitu gerakan menaikkan atau menurunkan petikemas dari dan ke atas chasis menggunakan alat Forklift, Side Loader atau Reach Stacer, yang dikerjakan di $C Y$ (Container Yard) atau lapangan.

4. Haulage yaitu gerakan container dari CFS atau $C Y$ ke dermaga atau sisi lambung kapal dengan menggunakan Chasis \& Head Truck (Trailer) atau sebaliknya.

5. Stevedoring merupakan gerakan petikemas dari chasis di dermaga ke palka kapal dengan menggunakan Gantry Crane/Port Crane/Ship Crane atau sebaliknya dari palka kapal ke chasis di dermaga.

6. Lashing merupakan kegiatan dari stevedoring, yang dikerjakan setelah semua petikemas dimuat di atas kapal, agar kedudukan petikemas satu dengan lainnya tidak bergerak.

7. Relokasi adalah gerakan memindahkan petikemas dalam satu lapangan $(C Y)$ untuk efisiensi yang disebabkan pemilik barang tidak segera mengeluarkan petikemas pada waktunya.

Berdasarkan penanganannya, cargo dibagi dua, yaitu general cargo dan special cargo. Berdasarkan cara pelayanan dan jenis produknya, cargo dibagi menjadi general cargo, special shipment (misalnya AVI, DG, LHO, HUM, VAL, VUN, PER, dan lain-lain), dan specialized cargo products (misalnya: express cargo, courier shipments, same day delivery) (IATA Regulation).

Menurut Sudjatmiko (2006: 67) jenis muatan (cargo) kapal laut dapat dibedakan menjadi beberapa golongan yaitu:

1. Jenis muatan General Cargo adalah muatan yang terdiri dari berbagai jenis barang dikemas dan dikapalkan secara potongan (per-stuk). General Cargo dibedakan menjadi: (a) Bulk Cargo adalah jenis muatan yang terdiri dari satu macam muatan yang tidak dikemas yang dikapalkan sekaligus dalam jumlah yang besar. (b) Homogenous Cargo adalah muatan yang terdiri satu macam barang yang dikapalkan sekaligus dalam jumlah besar dalam keadaan dikemas dengan karung beras atau sak semen.

2. Jenis muatan ditinjau dari sifat alamiahnya, yaitu jenis muatan padat, cair, dan gas yang dicairkan (LNG/Liquified Natural Gas).

3. Jenis muatan ditinjau dari segi ekonomi kapal dibedakan menjadi 2, yaitu: 1) Deadweight Cargo yaitu muatan yang ukuran volumenya kurang dari 40 kaki kubik dalam tiap ton (Long ton $=2.240 \mathrm{lbs}$ ); 2) Measurement Cargo, yaitu muatan yang ukuran (volumenya 40 kaki kubik atau lebih) setiap ton.

4. Special Cargo yaitu barang-barang kiriman yang memerlukan penanganan khusus (special handling). Jenis barang ini biasanya diangkut lewat angkutan udara dan harus memenuhi persyaratan khusus sesuai dengan regulasi IATA dan/atau pengangkut. Barang yang termasuk dalam kategori special cargo adalah AVI, DG, PER, PES PEM, HEA, dan lain-lain. 


\section{Sparkol Videoscribe}

Menurut Joyce dan B. White dalam Wulandari (2016: 63) "sparkol videoscribe is a great for creating short whiteboard style animations to explain certain concept, either by instructor or student", dapat diartikan bahwa videoscribe adalah software yang menciptakan animasi gaya papan tulis singkat untuk menjelaskan konsep tertentu baik dibuat oleh instruktur (pendidik) dan peserta didik. Sedangkan menurut wikipedia, Sparkol Videoscribe adalah software yang digunakan dalam membuat video dengan design animasi berlatar putih dengan sangat mudah dan menarik. Software ini dikembangkan pada tahun 2012 oleh sparkol Salah satu perusahaan yang ada di Inggris. Videoscribe mengembangkan Adobe Flash dan menghasilkan QuickTime Video dan Flash Video. Software ini menggunakan Cloud untuk penyimpanannya. Selain QuickTime dan Flash Video bisa dihasilkan dengan format gambar JPEG dan PNG.

Banyak sekali kegunaan sofware aplikasi videoscribe diantaranya bisa digunakan pendidik (guru atau dosen) sebagai pengantar pembelajaran, presentasi keperluan pendidik maupun peserta didik ataupun menunjukkan kemampuan berpikir dan mengkombinasikannya melewati video animasi.

Banyak macam tools-software aplikasi videoscribe diantaranya:

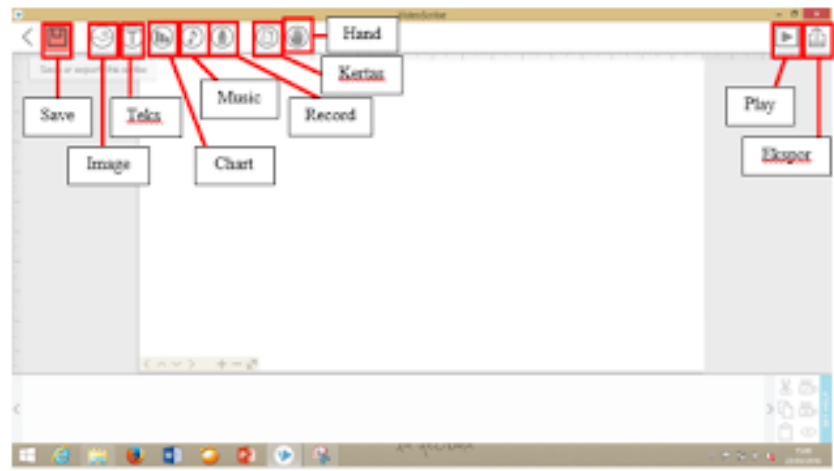

Gambar 1. Tools yang ada di software videoscribe (https://en.wikipedia.org/wiki/VideoScribe).

Tools Add : Untuk menambahkan project yang ingin di buat.

Save : Untuk menyimpan project.

Image : Untuk memilih gambar yang ditaruh divideoscribe.

Teks : Untuk memasukkan teks dalam videoscribe.

Chart : Untuk memasukkan diagram.

Music : Untuk memasukkan musik/suara.

Record : Untuk memasukkan rekaman suara.

Kertas : Untuk memasukkan warna/texture background.

Hand : Untuk mengganti gambar tangan.

Play : : Utuk memainkan video yang sudah dibuat.

Ekspor : Untuk mengekspor project menjadi bentuk video.

Bertolak dari uraian di atas, dalam kesempatan ini penulis bermaksud mengkaji tentang Upaya Meningkatkan Hasil Belajar Mahasiswa Melalui Simulasi Pelayanan Terminal Petikemas dalam Bidang Receiving Cargo Menggunakan 
Software Sparkol Videoscribe pada Mata Kuliah Manajemen Petikemas pada Prodi Ketatalaksanaan Pelayaran Niaga Akademi Maritim Yogyakarta.

\section{METODE}

Penelitian ini menggunakan pendekatan kualitatif dan kuantitatif. Hal ini didasarkan kepada kebutuhan penelitian ini yang menuntut peneliti untuk melakukan eksplorasi dalam rangka memahami dan menjelaskan masalah-masalah yang menjadi fokus masalah penelitian ini.

Pengumpulan data dan informasi dilakukan menggunakan metode observasi, angket dan studi dokumentasi. Metode yang digunakan peneliti adalah metode perancangan dan penelitian pengembangan (Design and Development Research).

Prosedur penelitian menggunakan pendekatan ADDIE (Analysis, Design, Development, Implementation, Evaluation). Pemilihan model ini didasarkan pada alasan bahwa tahapan-tahapan dasar desain pengembangan ADDIE sederhana, mudah dipelajari, simpel serta lebih mudah dipraktikkan dalam pengembangan media pembelajaran.

Instrumen penelitian yang digunakan berupa lembar komentar dan saran serta kuesioner. Kuesioner meliputi formulir penilaian untuk ahli dan penilaian untuk taruna. Instrumen penilaian kelayakan videoscribe pada penelitian ini menggunakan skala Guttman dengan alternatif yang diberi skor "ya " $=1$ dan "tidak" = 0

Penilaian kelayakan videoscrib menggunakan skala Sugiyono (2015), yaitu:

Tabel 1. Acuan Penilaian Validasi

\begin{tabular}{c|c}
\hline Presentase & Katagori \\
\hline $81 \%-100 \%$ & Sangat Layak \\
\hline $61 \%-80 \%$ & Layak \\
\hline $41 \%-60 \%$ & Cukup layak \\
\hline $21 \%-40 \%$ & Tidak Layak \\
\hline $0 \%-20 \%$ & Sangat Tidak layak \\
\hline
\end{tabular}

Penilaian angket dilakukan dengan metode:

$$
\text { Presentase } \%=\sum \text { skor yang diperoleh } \times 100 \%
$$

Hasil penilaian angket dibagi dalam kriteria kualitatif sebagai berikut:

Tabel 2. Range Presentase Kriteria Kualitatif

\begin{tabular}{c|c}
\hline Interval & Kriteria \\
\hline $81,25 \%>$ Skor $\leq 100 \%$ & Sangat Baik \\
\hline $62,50 \%>$ Skor $\leq 81,25 \%$ & Baik \\
\hline $43,75 \%>$ Skor $\leq 62,50 \%$ & Cukup Baik \\
\hline $25 \% \geq$ Skor $\leq 43,75 \%$ & Kurang Baik \\
\hline
\end{tabular}

Ada tidaknya peningkatan hasil belajar siswa dilihat dengan membandingkan minat belajar siswa sebelum dan sesudah diberikan treatment. Uji yang digunakan adalah uji $N$-gain (Susanto, 2012). Kategori peningkatannya adalah: 
Tabel 3. Kriteria Besarnya Faktor Gain

\begin{tabular}{c|c}
\hline Interval & Kriteria \\
\hline $\mathrm{g}>0,7$ & Tinggi \\
\hline $0,3 \leq \mathrm{g} \leq 0,7$ & Sedang \\
\hline $\mathrm{g}<0,3$ & Rendah \\
\hline
\end{tabular}

Secara ringkas, prosedur pengembangan media interaktif videoscribe digambarkan dalam lay out berikut ini.

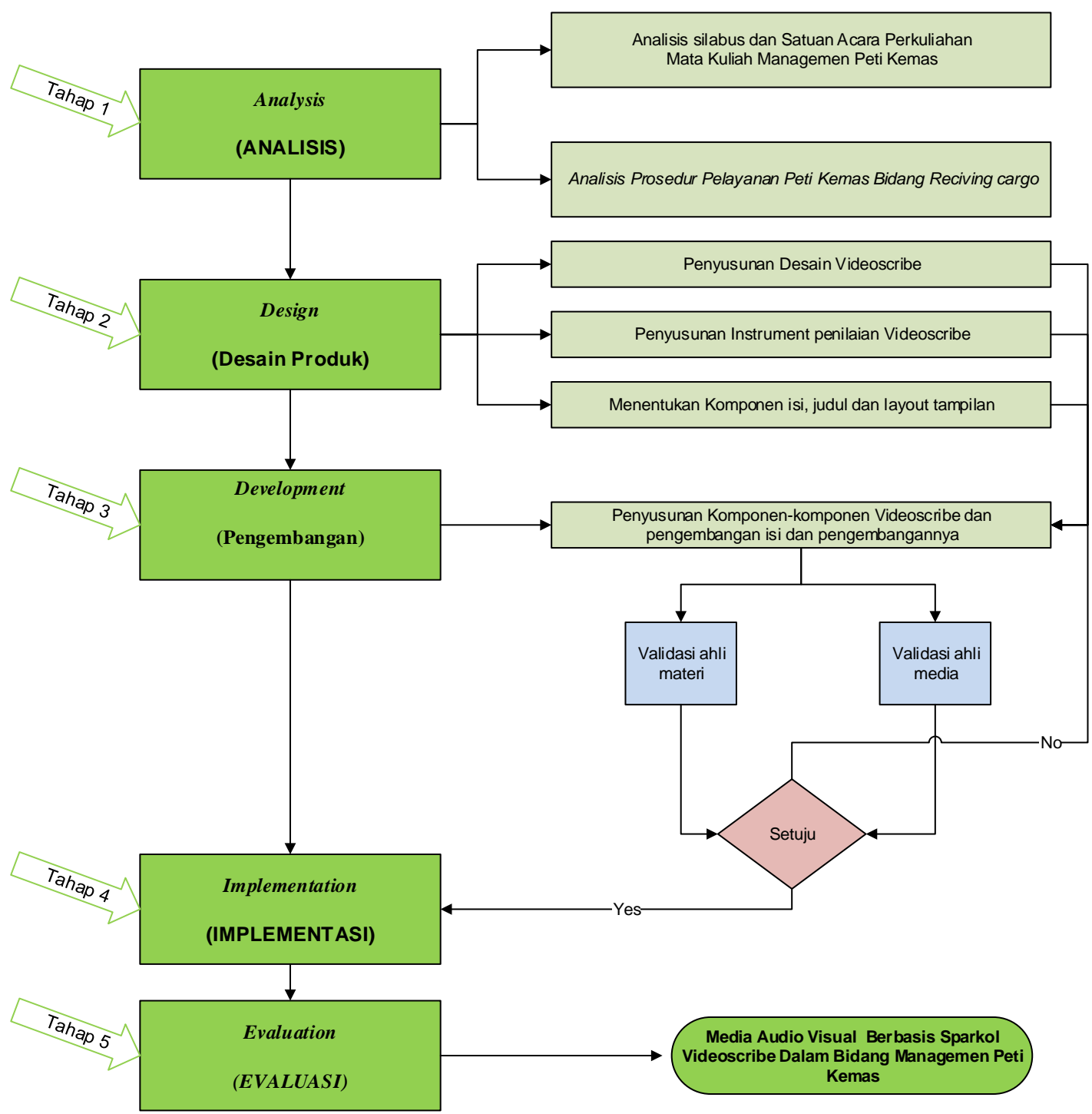

Gambar 2. Prosedur Pengembangan Media Interaktif Videoscribe 


\section{HASIL DAN PEMBAHASAN}

\section{Tahap Analysis}

Dilakukan 2 analisis yaitu analisis silabus dan SAP serta analisis prosedur pelayanan petikemas. Tujuan tahap ini agar produk yang dihasilkan sesuai kurikulum yang berlaku.

1. Analisis silabus dan SAP

Tujuan instruksional umum Mata Kuliah Manajemen Petikemas adalah mengetahui dasar manajemen, standarisasi, ukuran, jenis, prosedur pelayanan, dan manajemen petikemas.

2. Analisis prosedur pelayanan petikemas dalam bidang receiving cargo

Prosedur layanan penerimaan petikemas adalah:

a. Perencanaan pelanggan harus melengkapi dokumen:

1) Surat Permohonan Penerimaan Petikemas

2) Penyediaan Warkat Dana (Pembayaran di Depan) (masing-masing 4 lembar) untuk diserahkan kepa-da Export Service Staff(Petugas Layanan Ekspor), dalam waktu 6 sampai dengan 24 jam sebelum kapal datang.

b. Petugas Layanan Ekspor mencetak Job Order/CEIR (Container Equipment Interchange Receipt $=$ Tanda Terima Pergerakan Peralatan Petikemas) yang telah disetujui oleh Export Superintendent (Superintenden Ekspor). Lembar ke 1, 2, dan 3 CEIR diserahkan kepada pelanggan. Pelanggan menyerahkannya kepada pengemudi Head Truck.

c. Pengemudi Head Truck menuju ke In-Gate (Gerbang Masuk), bersama muatannya dan menyerahkan Job Order/CEIR serta salinan CTPS (Catatan Tanda Pengenal Surveyor)/PEB (Pemberitahuan Ekspor Barang) kepada Petugas Gate.

d. Petugas Gate memeriksa fisik petikemas dan mencetak In-Gate Terminal Job Slip (Lembar Kerja Terminal Gerbang Masuk), berdasarkan Job Order/CEIR, dan mengembalikan lembar ke 3 dan 4 kepada pengemudi Head Truck.

e. Pengemudi Head Truck menyerahkan In-Gate Terminal Job dan Job Order/CEIR kepada Petugas Tally Lapangan.

f. Petugas Tally Lapangan memerintahkan Operator RTG untuk mengangkat petikemas dari Chassis Head Truck ke Lapangan Penumpukan Petikemas, lalu mengkonfirmasi posisi petikemas ke dalam sistem komputer (HHT/Teklogix).

g. Pengemudi Head Truck menerima Job Order/CEIR dan In-Gate Terminal Job Slip dari Petugas Tally Lapangan dan menyerahkan In-Gate Terminal Job Slip dan Job Order/CEIR lembar ke-3 kepada Out-Gate Staff (Petugas Gerbang Keluar).

\section{Tahap Design}

Proses yang dilakukan pada tahap perancangan adalah persiapan pembuatan media pembelajaran dengan melakukan penyusunan desain videoscribe, penyusunan instrument penilaian sekaligus menentukan komponen isi, judul dan layout tampilan. Tahap ini meliputi: 
1. Penyusunan desain videocribe menggunakan alat bantu utama software pembuatan media yaitu Sparkol Videoscribe.

2. Penyusunan komponen isi, judul dan layout tampilan.

\section{Tahap Development}

Tahap ini merupakan tahap pengembangan media pembelajaran. Pada tahap ini media yang telah selesai dibuat diperiksa dan divalidasi oleh ahli media dan ahli materi agar dapat digunakan di dalam pembelajaran.

Validator terdiri dari dua ahli media dan satu ahli materi. Media pembelajaran harus melewati tahap validasi karena pada tahap ini media direvisi oleh validator dan diperbaiki oleh peneliti hingga media tersebut dianggap layak untuk digunakan dalam pembelajaran. Berikut adalah hasil validasi oleh ahli media:

Tabel 4. Hasil Validasi Mutu Teknis dan Aspek Media

\begin{tabular}{|l|c|c|c|c|c|c|}
\hline No & $\begin{array}{c}\text { Aspek yang } \\
\text { dinilai }\end{array}$ & Nilai Ahli 1 & Nilai Ahli 2 & $\begin{array}{c}\text { Nilai } \\
\text { Maksimal }\end{array}$ & $\begin{array}{c}\text { Rataan } \\
\text { Presentase }\end{array}$ & Ket. \\
\hline 1. & Mutu Teknis & 13 & 14 & 20 & $67.50 \%$ & Baik \\
\hline 2. & AspekMedia & 41 & 40 & 52 & $77.88 \%$ & Baik \\
\hline
\end{tabular}

Berdasarkan hasil dari validasi Mutu Teknis dan Aspek Media di atas, diperoleh hasil penilaian mutu teknis $67.50 \%$ yang masuk dalam kategori baik, dan nilai aspek media $77.88 \%$ yang masuk dalam kategori sangat baik. Data tersebut menunjukkan bahwa media pembelajaran menggunakan sparkol videoscribe pada mata kuliah Manajemen Petikemas dikategorikan baik dilihat dari mutu teknis maupun dari aspek media.

Tabel 5. Hasil Validasi Aspek Media dan Kesesuaian Materi

\begin{tabular}{|c|l|l|c|c|c|l|}
\hline No & \multicolumn{1}{|c|}{$\begin{array}{c}\text { Aspek yang } \\
\text { dinilai }\end{array}$} & $\begin{array}{c}\text { Nilai } \\
\text { Ahli 1 }\end{array}$ & $\begin{array}{c}\text { Nilai } \\
\text { Ahli 2 }\end{array}$ & $\begin{array}{c}\text { Nilai } \\
\text { Maksimal }\end{array}$ & $\begin{array}{c}\text { Rataan } \\
\text { Presentase }\end{array}$ & \multicolumn{1}{|c|}{ Ket. } \\
\hline 1. & Aspek Media & 26 & 36 & 36 & $86.11 \%$ & $\begin{array}{l}\text { Sangat } \\
\text { Baik }\end{array}$ \\
\hline 2. & $\begin{array}{l}\text { Aspek } \\
\text { Kesesuaian } \\
\text { Materi }\end{array}$ & 11 & 15 & 16 & $81.25 \%$ & $\begin{array}{l}\text { Sangat } \\
\text { Baik }\end{array}$ \\
\hline
\end{tabular}

Berdasarkan hasil dari validasi ahli materi di atas, diperoleh hasil penilaian aspek media $86.11 \%$ dan aspek kesesuaian materi $81.25 \%$ dimana kedua aspek tersebut masuk kedalam kategori sangat baik. Data tersebut menunjukkan bahwa media pembelajaran menggunakan sparkol videoscribe pada mata kuliah Manajemen Petikemas termasuk dalam kategori sangat baik.

\section{Tahap Implementation}

Tahap implementation merupakan tahap dimana media yang telah diproduksi digunakan dalam pembelajaran. Media pembelajaran menggunakan sparkol videoscribe digunakan pada mata kuliah Manajemen Peti kemas. Media tersebut digunakan selama dua hari hari oleh dosen pengampu mata kuliah Manajemen Peti Kemas. 


\section{Tahap Evaluation}

Pada tahap ini dilakukan klarifikasi penggunaan media dalam meningkatkan minat belajar taruna. Pengukuran peningkatan minat belajar dilakukan dengan pemberian angket minat pada taruna, dimana angket itu tersebut diberikan dua kali perlakuan yaitu, sebelum menggunakan media dan sesudah menggunakan media (pretest dan posttes).

Angket minat diberikan kepada 10 taruna. Angket minat diberikan kepada taruna guna mengetahui minat yang dimiliki taruna sebelum dan sesudah penggunaan media menggunakan sparkol videoscribe. Pengukuran peningkatan minat belajar taruna dilakukan dengan menggunakan uji n-gain agar dapat mengetahui seberapa besar peningkatan minat yang terjadi pada taruna setelah menggunakan media pembelajaran menggunakan sparkol videoscribe. Berikut adalah hasil pengukuran peningkatan minat belajar taruna.

Tabel 6. Hasil Pengukuran Minat Belajar dengan Uji N-Gain

\begin{tabular}{|l|l|l|}
\hline \multicolumn{1}{|c|}{ No } & \multicolumn{1}{|c|}{ Perlakuan } & \multicolumn{1}{c|}{ Taruna } \\
\hline 1. & Rata- rata nilai Pretest & 64.67 \\
\hline 2. & Rata- rata nilai Posttest & 79.67 \\
\hline 3. & Nilai Maksimal & 92 \\
\hline 4. & N-Gain & 0.43 \\
\hline 5. & Kesimpulan & Sedang \\
\hline
\end{tabular}

Tabel di atas menunjukkan nilai rata-rata minat belajar taruna sebelum menggunakan media adalah sebesar 64.67 dan setelah menggunakan media pembelajaran svideoscribe berubah menjadi 79.67. Berdasarkan hasil uji $\mathrm{N}$-gain, peningkatan minat belajar taruna mendapat nilai gain sebesar 0.43 . Nilai ini jika dimasukkan ke dalam kriteria faktor gain maka termasuk dalam kategori sedang.

\section{SIMPULAN}

\section{Kesimpulan}

Berdasarkan pembahasan yang telah dilakukan dapat diambil kesimpulan sebagai berikut: Pelaksanaan pengembangan media pembelajaran menggunakan sparkol videoscribe dapat meningkatkan hasil belajar mahasiswa pada Mata Kuliah Manajemen Petikemas pada Prodi Ketatalaksanaan Pelayaran Niaga Akademi Maritim Yogyakarta. Hal ini dapat diketahui dari dua fakta, yaitu:

1. Berdasarkan hasil dari validasi ahli media, diperoleh hasil penilaian mutu teknis $67.50 \%$ yang masuk dalam kategori baik dan nilai aspek media $77.88 \%$ yang masuk dalam kategori sangat baik.

Berdasarkan hasil dari validasi ahli materi, diperoleh hasil penilaian aspek media $86.11 \%$ dan aspek kesesuaian materi $81.25 \%$ dimana kedua aspek tersebut masuk kedalam kategori sangat baik.

3. Adanya peningkatan nilai rata-rata minat belajar taruna sebelum dan sesudah menggunakan media sparkol videoscribe. Nilai minat sebelum menggunakan media sparkol videoscribe adalah sebesar 64.67. Nilai minat setelah menggunakan media pembelajaran videoscribe berubah menjadi 79.67 . 
Berdasarkan hasil uji $\mathrm{N}$-gain, peningkatan minat belajar taruna mendapat nilai gain sebesar 0.43 yang termasuk dalam kategori sedang.

\section{Saran}

Berdasarkan simpulan di atas, maka disarankan:

1. Kepada dosen Mata Kuliah Manajemen Petikemas disarankan untuk meningkatkan hasil belajar mahasiswa dengan menggunakan media sparkol videoscribe karena terbukti media ini telah mampu meningkatkan hasil belajar mahasiswa yang dijadikan obyek penelitian ini.

2. Kepada mahasiswa disarankan untuk banyak berlatih membuat materi presentasi menggunakan media sparkol videoscribe. Melalui latihan yang intensif, mahasiswa akan mampu meningkatkan kualitas presentasi dan hasil belajarnya secara berarti.

\section{DAFTAR PUSTAKA}

Arsyad, Azhar. 2011. Media Pembelajaran. Cetakan ke-15. Jakarta: Rajawalli Pers. Arwinas, 2000. Petunjuk Penanganan Kapal Dan Barang di Pelabuhan. PT Persero Pelabuhan Indonesia II. Jakarta.

Dick and Carey. 1996. The Sistematic Design of Instruction. Fourth Edition: Harper Collins College Published.

IATA Regulation.

Lantip, Prasojo Diat dan Riyanto. 2011. Teknologi Informasi Pendidikan. Yogyakarta : Gava Media.

Keputusan Direktur Jenderal Perhubungan Laut Nomor UM.002/38/18/DJPL 11 tentang Standar Kinerja Pelayanan Operasional Pelabuhan.

Keputusan Menteri Perhubungan Nomor KM 14 Tahun 2002 tentang Penyelenggaraan Dan Pengusahaan Bongkar Muat Barang Dari dan ke Kapal.

M.S., Amir, 1997. Petikemas. Jakarta: Pustaka Binaman Pressindo.

Santoso, Banu. H. 1998. Port terminal Operation. Semarang: Penerbit P3M Akademi Maritim Nasional Indonesia (AMNI).

Sudjatmiko, F.D.C. 2006. Sistem Angkutan Petikemas. Jakarta: Janiku Pustaka.

Sugiyono. 2015. Metode Penelitian Pendidikan Pendekatan Kuantitatif, Kualitatif dan $R \& D$. Bandung : Alfabeta.

Suyono, R.P. 2007. Shipping Pengangkutan Intermodal Ekspor-Impor Melalui Laut. Edisi ke-empat. Jakarta: Penerbit PPM.

Warpani, Suwardjoko P. 2002. Pengelolaan Lalu Lintas \& Angkutan Barang. Bandung: Penerbit ITB.

Wulandari, Dyah. 2016. Pengembangan Media Pembelajaran Menggunakan Sparkol Videoscribe Dalam Meningkatkan Minat Belajar Siswa Pada Mata Pelajaran IPA Materi Cahaya Kelas VIII Di SMP Negeri 01 Kerjo Tahun 2015/2016 http//:lib.unnes.ac.id.html, diakses 14 Februari 2018.

"Pelayanan Terminal Peti Kemas, http://ggiez.blogspot.co.id/-2014/09/pelayananterminal-peti-kemas.html. 
"Syarat dan Jenis Kargo Udara", https://www.kargo.co.id/blog/-syarat-dan-jeniskargo-udara.

"Videoscribe", https://en.wikipedia.org/wiki/VideoScribe. 